\title{
“Estes povos pastoris": entre a aldeia de Vilarinho da Furna e a literatura de Miguel Torga
}

\section{Peter Haysom \\ University of Nottingham/Midlands3Cities AHRC Doctoral Training Partnership}

Resumo: A aldeia de Vilarinho da Furna, localizada no extremo-norte de Portugal, foi uma das últimas aldeias comunitárias no país (ou seja, uma povoação de democracia concentrada com um regime de partilha de propriedade), funcionando como um símbolo das origens e dos valores puros das comunidades ibéricas seculares. O interesse cultural e etnográfico para com esta povoação intensificou-se durante e depois do processo de submersão da aldeia (1969-1972) pelo regime ditatorial da época. A este propósito, considerar Vilarinho da Furna à luz da literatura de Miguel Torga (1907-1995), conhecida pela sua evocação de espaços geográficos e comunidades rurais, é extremamente produtiva de um ponto de vista geocrítico. Vários textos de Torga nos seus Diários refletem, e contribuem para, um sentimento de afeição e topofilia para com a comunidade de Vilarinho e o seu entorno natural, baseado no comportamento harmonioso dos aldeões e no valor simbólico da povoação. Para além disso, o conto "Barragem" (1951) transforma o espaço real daquela aldeia num imaginário literário, através da sua oscilação entre representação ficcional e referente geográfico real. Finalmente, pode-se afirmar que a literatura de Miguel Torga sobre Vilarinho influenciou, em certa medida, o próprio espaço geográfico da antiga comunidade, assim como a percepção cultural e a memória coletiva do lugar em questão.

Palavras-chave: Vilarinho da Furna; Miguel Torga; topofilia; referencialidade; imaginário 


\begin{abstract}
The village of Vilarinho da Furna, located in the extreme North of Portugal, was one of the last remaining communitarian villages in the country (in terms of its concentrated democratic structure and its sharing of property and land), which acted as a symbol of the pure values and origins of centuries -old Iberian communities. The considerable cultural and ethnographic interest towards this settlement intensified as the process of submerging the village (1969-1972) was orchestrated by the dictatorial regime of the time.

In this regard, from a geocritical point of view it is extremely productive to consider Vilarinho through the literature of Miguel Torga (1907-1995), a writer known for evoking geographical spaces and rural communities. Several of Torga's texts from his Diários reflect, as well as contribute towards, feelings of affection and topophilia towards the community of Vilarinho da Furna and its natural surroundings, based on the harmonious behaviour of the villagers and the symbolic value of the settlement. In addition, the short story "Barragem" (1951) transforms the real space of that village into a literary imaginary, by oscillating between a fictional representation and the real geographical referent. Finally, it can be argued that the literature of Torga about the village has, to a certain degree, influenced the actual geographical space of the former community as well as the cultural perceptions and collective memory of the space in question.
\end{abstract}

Keywords: Vilarinho da Furna; Miguel Torga; topophilia; referentiality; imaginary

Dentro da memória coletiva do Portugal rural, encontra-se a história de Vilarinho da Furna, uma antiga aldeia comunitária em Portugal que foi forçosamente evacuada entre 1969 e 1970 e afundada em 1971, por ordem do Estado Novo, para construir a Barragem que é hoje conhecida como Vilarinho das Furnas. ${ }^{1}$ Apesar dos edifícios da antiga aldeia serem geralmente visíveis quando o nível da água na albufeira é baixo, o atual aproveitamento hidrológico da barragem impede que o visitante de hoje veja as ruínas desta antiga comunidade. Resta-nos contemplar o espaço e imaginar a aldeia de Vilarinho da Furna que jaz debaixo da superfície através do nosso laço afetivo com este lugar (ou seja, a nossa topofilia) e o imaginário geográfico associado ao mesmo sítio.

De facto, Vilarinho da Furna tem cativado a memória cultural coletiva de muitos portugueses ao longo de vários anos, devido aos valores comunitários que representava e ao sentimento de perda que a sua história continua a suscitar. Bem antes e bem depois do 
esvaziamento forçado da aldeia, esta comunidade inspirou numerosos projetos: um filme realizado por António Campos (Vilarinho das Furnas, 1971), a inauguração do Museu Etnográfico de Vilarinho da Furna em $1989^{2}$ (e também um projecto mais recente de criar um museu subaquático), ${ }^{3}$ vários estudos históricos e sociológicos sobre a aldeia, ${ }^{4}$ assim como obras literárias mais recentes tais como o romance Rio Homem (2010) de André Gago. No entanto, é na literatura de Miguel Torga que esta povoação comunitária surge repetidamente entre os anos quarenta e setenta, referida pelo autor explicitamente e também evocada através de uma interpretação ficcional da comunidade real, interpretação essa que acabaria por prever o verdadeiro destino de Vilarinho da Furna.

Por conseguinte, este ensaio considerará a relação entre determinados textos de Miguel Torga e a aldeia de Vilarinho da Furna, à luz das teorias de Yi-Fu Tuan relativamente à topofilia ${ }^{5}$ e de Bertrand Westphal e Robert T. Tally Jr. no que diz respeito à geocrítica. ${ }^{6}$ Especificamente, concentrar-se-á em três questões fundamentais desta relação espaçotexto: em primeiro lugar, o sentimento de topofilia que Torga exprime (e inspira) nos seus Diários para com a aldeia de Vilarinho da Furna, que se encontra imbuída de valor simbólico e de nostalgia nos seus textos; depois, a construção de um imaginário geográfico e de uma relação dialética associada à mesma comunidade, através de uma apresentação ficcional da aldeia no conto "Barragem" (1951); finalmente, a maneira como estes textos de Torga relacionados com Vilarinho da Furna têm influenciado ou tido impacto sobre as percepções culturais da antiga aldeia e sobre o próprio espaço envolvente.

Antes de considerar Miguel Torga, será importante começar por explicar a importância de Vilarinho da Furna, localizado no Concelho de Terras de Bouro, distrito de Braga, região do Minho. Tal como notado no estudo etnológico de Jorge Dias em 1948, e no livro de Manuel de Azevedo Antunes de 1985, esta povoação, cuja origem já foi datada da época romana (cf. Antunes 1985: 9), salientou-se pelo seu isolamento geográfico no país, a proximidade entre os aldeões e o forte sistema de organização comunitária (a partilha e regulamentação de terras, gado, trabalhos e lucro, com mecanismos democráticos de governação local) que estruturava a aldeia até a sua destruição: ${ }^{7}$ 
[0] aspecto mais interessante da vida deste povo é, fora de dúvida, a organização social antiquíssima, que ainda hoje se apresenta bastante perfeita. (...) Vilarinho representa uma espécie de estado independente, com governo e legislação próprios. (...) [E]m Vilarinho nós encontramos um regime económico e político extraordinariamente simples, em que a terra não arável pertence a todas as famílias (...). (Dias 1981: 39, 81, 304)

Será fundamental referir, por um lado, que o comunitarismo identificado em Vilarinho da Furna não constituía um caso único, devido aos traços da mesma estrutura social em outras aldeias portuguesas (cf. Dias 1981: 84; Martins 1972: 7) ${ }^{8}$ e, antigamente, em vários países europeus (cf. Dias 1981: 19). Por outro lado, Vilarinho tem uma importância particular para vários autores por ter mantido o modelo comunitário num estado mais "perfeito" (ibidem), funcionando como um símbolo vivo da antiga harmonia presente nas relações humanas:

Vilarinho da Furna era uma das últimas e mais típicas aldeias comunitárias da Europa. (...) [U]ma relíquia da velha organização comunitária, hoje agonizante, mas outrora muito difundida na Europa. Mesmo sem ser um caso único, o comunitarismo de Vilarinho era, pelo menos, um caso invulgar. (Antunes et al. 2010: 15)

Por sua vez, Antunes considera que o continuado interesse em Vilarinho da Furna, antes e depois da sua destruição, decorre desta especificidade da aldeia em combinação com o sentimento de perda associado à comunidade: "Não fosse a sua riqueza etnográfica e a construção da barragem que pôs fim à sua existência e Vilarinho da Furna seria hoje uma aldeia esquecida, anónima como o seu passado, qual pérola perdida na vastidão das se rras do Minho" (1985: 11). Acrescentemos mais um factor: a literatura de Miguel Torga.

Se é verdade que este célebre autor nortenho, de São Martinho de Anta, Trás-osMontes, é tipicamente associado à sua terra de origem (cf. Santana 2008: 156), exprimindo no seu Diário VI “um apego sentimental à capelinha da aldeia onde nasci” (Torga 1978b: 14 15), Miguel Torga tem sido profundamente ligado ao sentimentalismo pela geografia em numerosos ensaios críticos, ${ }^{9}$ sentimentalismo esse que é corroborado pelo próprio autor no Diário VIII: "Sou, na verdade, um geófago insaciável, necessitado diariamente de alguns 
quilómetros de nutrição. Devoro planícies como se engolisse bolachas de águas e sal, e atiro-me às serranias como à broa da infância" (1976: 149). Já estas afirmações do autor indicam um certo grau de topofilia, um fenómeno definido por Yi-Fu Tuan como "the affective bond between people and place or setting" (1974: 4); porém, como Tuan indica, este sentimento torna-se mais intenso quando associado a um território limitado e particular: "topophilia rings false when it is claimed for a large territory. (...) The home region (pays) has historical continuity, and it may be a physiographic unit (a valley, coast, or limestone outcrop) small enough to be known personally" (idem: 101). Neste sentido, podese argumentar que os sentimentos de afeição que Torga articula para com a geografia podem ser precisamente localizados: no presente ensaio, interessa-nos a topofilia de Torga em relação ao espaço limitado de Vilarinho da Furna.

Ao observar as localizações e as datas registadas por Torga nos seus Diários, verificase que o escritor escreve sobre Vilarinho e as áreas envolventes quatro vezes: em $1945 \mathrm{e}$ 1948, bem antes da construção da barragem; em 1968, aquando das últimas preparações para o esvaziamento e submersão da aldeia; e em 1976, depois da destruição da antiga povoação. Para além destas referências explícitas àquela localização nos Diários, o autor menciona a mesma comunidade passageiramente no seu livro Portugal (1951) e, no seu conto "Barragem" (Pedras Lavradas, 1951), retrata Ervedosa, uma aldeia comunitária fictícia que é destruída pela construção de uma barragem - vinte anos de acontecer o mesmo a Vilarinho da Furna. Na escrita de Miguel Torga, Vilarinho alterna entre as interpretações reais e ficcionais, entre o espaço físico e o imaginário.

Podemos considerar, nesta conjuntura, os laços afetivos que Torga exprime, e também constrói, entre o ser humano e esta aldeia comunitária. Em 1945, aquando da primeira visita registada do autor a Vilarinho, a paisagem geográfica envolvente é descrita com uma linguagem bucólica e paradisíaca, exprimindo as impressões pessoais do autor: “0 vale do Homem, ao fundo, fértil, verde e brilhante, com lagos de água cristalina a reluzir de onde em onde, parece a terra da promissão. Um silêncio preservado rodeia tudo de paz" (Torga 1973a: 107). Simultaneamente, canalizando as palavras do seu guia local, Torga contempla a relação emocional entre o aldeão furnense e o seu entorno natural: "o meu 
contrabandista, então, perde-se no meio de tanta grandeza e de tanta liberdade, e monologa: - Acredite que não trocava a minha vida pela de nenhum rei! Gosto tanto destas penedias que, se me tirassem um pedaço a uma dava conta!" (ibidem). Desta forma, o autor articula o sentimento de profundo apego dos furnenses à sua terra, através da harmonia entre ser humano e espaço.

Em Agosto de 1968, durante a última visita de Miguel Torga ao Vilarinho da Furna antes da evacuação da comunidade, o Diário XI reflete a relação agradável que tinha desenvolvido, ao longo de vários anos, entre Torga e a aldeia, e a tranquilidade e energia positiva que a mesma inspirava no autor:

[G] ostava de ir de vez em quando até Vilarinho presenciar a harmonia social em pleno funcionamento (...). Dava-me contentamento ver a lei moral a pulsar quente e consciente nos corações, e a entreajuda espontânea a produzir os seus frutos. Regressava de lá com um pouco mais de esperança nos outros e em mim. (1978a: 11-12, itálicos meus)

Através deste tipo de comentários sobre um determinado espaço/comunidade, Torga exprime sentimentos de afeição que poderíamos catalogar como topofilia, no sentido concebido por Yi-Fu Tuan de existir um elo afetivo entre as pessoas e um determinado lugar ou cenário. De facto, a espécie de amor que este autor exprime pela aldeia de Vilarinho de Furna é particularmente relevante e topofílico, porque se associa a fortes memórias do comunitarismo antigo: "The appreciation of landscape is more personal and longer lasting when it is mixed with the memory of human incidents" (Tuan 1974: 95).

Na verdade, é importante salientar que os sentimentos afetivos que Torga confere a esta aldeia decorrem da natureza invulgar da sua estrutura humana: o sistema comunitário. Já Isabel Maria Fidalgo Mateus e José Manuel Cymbron, nas suas respetivas teses de doutoramento, notaram a influência direta de Vilarinho da Furna, e também de outras aldeias com características comunitárias, ${ }^{10}$ sobre a filosofia política do autor: "Pensamos que este encontro com as serras, com a água, com a vegetação e, essencialmente, com o comunitarismo de Vilarinho da Furna, explica as constantes idas de Torga para o Gerês no período mais rico da sua produção literária” (Cymbron 2015: 452). ${ }^{11}$ Considerando que, 
como vários estudos de Miguel Torga sublinham, a "experiência comunitária" é um tema repetido na ficção deste autor (cf. Santana 2008: 157; Lousada 2003: 315), não seria de surpreender que a aldeia mais representativa do comunitarismo em Portugal seja uma localização que é privilegiada pelo autor nas suas viagens.

Desta forma, pode-se afirmar que a aldeia de Vilarinho, enquanto espaço retratado por Torga, é imbuída de uma forte importância simbólica, funcionando com um exemplo de determinados valores democráticos e de modos puros de viver em comunidade. Tendo declarado, na sua visita de 1945 à Serra Amarela (ao redor da aldeia), que a área representava “o Portugal nuclear, a Ibéria na sua pureza essencial e granítica” (Torga 1973a: 106), o autor também comentou que o sistema político-social vigente em Vilarinho da Furna simbolizava a democracia que ele desejava espelhar para outras regiões de Portugal, no contexto do salazarismo (Mateus 2006: 162). ${ }^{12}$ Vejamos o seu texto escrito em Agosto de 1968:

[E]u ainda sou pela ordem voluntária no ócio e no trabalho, por uma disciplina cívica consentida e prestante, a que os heréticos chamam democracia. De maneira que gostava de ir de vez em quando até Vilarinho presenciar a harmonia social em pleno funcionamento, sem polícias fardados ou à paisana. (Torga 1973b: 11-12, itálico meu)

Assim sendo, a aldeia em questão funciona em Torga como um modelo social idealizado, o símbolo de uma estrutura comunitária que é simultaneamente uma "amostra viva dum passado remoto”, nas palavras de Jorge Dias (1981: 307), e um projeto político para o futuro do país. Em alguns casos, por exemplo no seu poema "Requiem" (escrito em 1976, depois da submersão de Vilarinho), Torga chega a sacralizar a antiga comunidade ("Esse mundo sagrado / Onde a vida era um rito demorado" [Torga 1986: 154]), imbuindoa de um simbolismo divino.

Na verdade, o valor simbólico com o qual a geografia é imbuída em várias obras de Miguel Torga já foi identificado por Vitor Lousada, no seu texto Miguel Torga: O Simbolismo do Espaço Telúrico e Humanista nos Contos (2003), e também por Paulo Carvalho: "A veneração pelos alicerces mais arcaicos da identidade e da memória nacional conduziu 
Miguel Torga aos lugares mais recônditos e simbólicos de Portugal” (Carvalho 2008: 82). Mais especificamente, Cymbron considera que Vilarinho é um de vários espaços (urbanos e rurais) em Portugal que, por diferentes razões, funcionam como espaços-símbolos na escrita de Torga, representando “o paradigma a seguir" (2015: 468). Mais do que outras aldeias, porém, Vilarinho da Furna surge na escrita de Torga como um espaço simbólico e sagrado de preferência porque terá representado mais fielmente e explicitamente o sistema comunitário no século vinte. Se para Lousada "a sacralidade, [em vários] contos torguianos, é a vida comunitária, a genuína tradição do nosso comunitarismo rural" (2003: 320), as repetidas referências explícitas a Vilarinho na obra de Torga relacionam-se fortemente com a sua representação do comunitarismo.

Ora, a interpretação de um determinado espaço como símbolo é também característico de uma intensa forma de topofilia, segundo a teoria de Tuan: "Topophilia is not the strongest of human emotions. When it is compelling we can be sure that the place or environment has become the carrier of emotionally charged events or perceived as a symbol" (1974: 93). Na interpretação literária de Vilarinho por Torga, a aldeia comunitária assume um valor simbólico devido às experiências do autor e ao significado histórico da povoação: "A symbol is a repository of meanings. Meanings arise out of the more profound experiences that have accumulated through time" (idem: 145). Segundo o raciocínio de Tuan, por ter sido construída dentro de um vale (o Vale do Homem), Vilarinho simboliza, literalmente, as origens das primeiras comunidades humanas ("it was in the valleys and basins of moderate size that mankind took the first steps toward agriculture and to sedentary life in large village communities" [idem: 117]), assim como uma pureza natural, vitalícia e materna: "Symbolically the valley is identified with the womb and shelter. Its concavity protects and nurtures life" (ibidem). Por conseguinte, pode-se afirmar que Torga associa à aldeia de Vilarinho um sentimento topofílico que decorre tanto das suas condições naturais como da especificidade da sua história humana.

Esta afeição relacionada com a geografia local é ainda reforçada pelo sentimento de perda que o autor evoca relativamente à destruição iminente da aldeia comunitária, refletindo a tendência mais ampla do escritor de ilustrar a degradação das comunidades 
rurais em Portugal devido a fenómenos económicos e à intervenção do Estado Novo (cf. Carvalho 2008: 80-81). No acima referido texto de 1968, o autor evoca o intenso sofrimento emocional vivido pelos furnenses ao evacuarem a sua aldeia natal para viverem noutras comunidades: "O esfacelamento interior que vai sofrer aquela gente, desenraizada no mundo, com todas as amarras afectivas cortadas, sem mortos no cemitério para chorar as lajes afeiçoadas aos pés para caminhar, já nem falo" (Torga 1973a: 12). Neste texto, assim como em outras obras que se referem indiretamente a Vilarinho da Furna, Torga reflete a tristeza e a emoção topofílica dos aldeões, pertante a destruição da sua terra e a necessidade de abandoná-la. Voltando a Tuan, a topofilia perante um lugar de habitação implica um profundo destroço emocional ao ser despojado do sítio:

A person in the process of time invests bits of his emotional life in his home, and beyond the home in his neighborhood. To be forcibly evicted from one's home and neighborhood is to be stripped of a sheathing, which in its familiarity protects the human being from the bewilderments of the outside world. (1974: 99)

Do mesmo modo, Miguel Torga articula o profundo sentimento de perda dos furnenses ao serem desalojados da sua terra natal e da sua vivência comunitária, sentimento esse que aparece tanto nas representações reais da aldeia como no imaginário ficcional do autor.

De facto, se os Diários de Torga constituem uma espécie de itinerário ou literatura de viagem do autor (cf. Mateus 2006; Cymbron 2015), pode-se afirmar que o escritor já explora as potencialidades culturais de Vilarinho da Furna enquanto referente geográfico e espaço de memória coletiva. Consideremos as observações de Maria de Fátima Outeirinho, relativamente à literatura de viagem:

Com efeito, a literatura de viagem constrói-se sobre a importância do referente espacial, sobre um espaço percorrido, no confronto com um imaginário herdado, posto à prova na vivência do seu viajante que por sua vez o trabalha, revisitando-o, para o reproduzir ou redescrever. (...) 0 texto de viagem organiza-se não apenas em relação a um referente espacial situado geograficamente num mapa físico, mas também em relação a um referente literário, pictórico ou fílmico que acolhe e 
trabalha um imaginário sobre uma espacialidade construída culturalmente, ancorando-se numa memória coletiva partilhada. (Outeirinho 2016: 195-197)

Dito isto, não é apenas nos textos de Miguel Torga que referenciam Vilarinho explicitamente que se observa "uma espacialidade construída cuturalmente". Isto (talvez) porque, a acreditar nas próprias palavras de Torga publicadas no Diário I (1941), o autor sentiu algum desconforto com a utilização de uma geografia limitada na literatura, criticando a circunstancialidade de vários grandes escritores portugueses: "O que me faz desesperar na leitura de Camilo e Gil Vicente, os dois génios mais representativos das nossas letras, é a sua falta de universalidade. (...) [C] hega-se ao fim com a sensação de que se passou apenas um bom dia no Cartaxo ou na Foz" (1989: 187). De facto, a célebre afirmação de Torga de que “o universal é o local sem paredes” (1990: 11) poderá ajudarnos a compreender melhor a relação que este autor pretende construir entre uma comunidade específica e limitada (tal como Vilarinho da Furna) e um paradigma universal, para a qual o "local" contribui. Por outro lado, o posicionamento de Torga entre um determinado referencial geográfico real e uma alegoria mais ampla pode ser bastante ambivalente, tal como o seu poema "A um carvalho" (1951) indica:

Eis o pai da montanha, o bíblico Moisés

Vegetal!

Fala com Deus também, deste Sinai

De granito...

Dele recebeu a graça natural

De ter formas reais e ser um mito. (1974: 115, itálico meu)

Ou seja, na perspetiva do autor, um determinado espaço físico, mesmo sendo limitado e minucioso, poderá servir como uma metáfora para fenómenos humanos ou naturais mais amplos, chegando a ter um estatuto mítico apesar do seu enraizamento na geografia real. Paralelamente, estes versos implicam que as interpretações ficcionais de um espaço real podem questionar ou ultrapassar os limites geográficos iniciais, tal como podemos verificar ao considerarmos a relação entre a ficção de Torga e Vilarinho da Furna.

Especificamente, o conto “Barragem”, da coletânea Pedras Lavradas (1951), tem uma 
curiosa relação dialética com a história verídica da destruição de Vilarinho, tendo sido escrito vinte anos antes da submersão da aldeia. Baseada numa aldeia ficcional chamada Ervedosa, ${ }^{13}$ este conto de Torga retrata uma povoação com orgãos governativos democraticamente eleitos a nível local, e uma divisão equitativa da atividade pastoril:

Comunitária desde tempos imemoriais, ninguém ali podia alargar os braços e estrangular o vizinho. (...) $[\mathrm{N}]$ o tocante à ordem e aos meios de produção cada qual tinha de dar contas à colectividade. Eleitos, os dirigentes prestavam contas dos seus actos em conselhos da povoação. Ninguém podia escusar-se ao mando nem à obediência. (1951: 155-159)

Neste sentido, se a aldeia ficcional representado neste conto corresponde a um ideal político utópico, na ótica de Maria Manuel Lisboa (“[o]rganized along co-operative rather than capitalist lines, inward-looking rather than expansionistic, introspective rather than imperialistic, Ervedosa approximates to the utopian anarchic-syndicalist commune" [2000: 37]), à semelhança do valor simbólico de Vilarinho nos Diários de Torga, Ervedosa também é praticamente idêntica a Vilarinho no que se refere aos pormenores da sua estrutura comunitária (cf. Dias 1981), e das suas circunstâncias geográficas: "Isolada e distante do mundo, vivia do pastoreio e da minguada cultura das terras ribeirinhas de aluvião" (Torga 1951: 155).

Simultaneamente, esta narrativa dos anos cinquenta, que documenta o desmembramento de uma comunidade e a sua dispersão à diáspora (cf. Lisboa 2000: 38), antecipa o fim da própria aldeia de Vilarinho nas décadas seguintes, quando as entidades governamentais ficcionais começam a paulatina construção de uma barragem e de uma albufeira: "Primeiro, as medições; depois, as sondagens; a seguir, as avaliações; por fim, a construção ciclópica do dique, na garganta do rio" (Torga 1951: 155). Neste retrato da destruição de Ervedosa, Torga remete para os mesmos sentimentos topofílicos, de perda e de trauma emocional que, como já vimos, Torga atribuiria aos aldeões de Vilarinho da Furna em 1968: "Aí romperam gritos dilacerados de cada alma, a [sic] ainda hoje, pelas quebradas, parece viver o eco dessa angústia de fim, que a guarda, de armas aperradas, 
tornou impotente" (idem: 158). Assim, nesta aldeia fictícia, o destino de Vilarinho na vida real é prognosticado de forma perculiarmente perspicaz.

Evidentemente que esta afinidade entre a aldeia comunitária de Ervedosa em "Barragem" e a história de Vilarinho da Furna não decorre apenas da coincidência. Tal como notado por Cymbron, a comunidade retratada no conto de 1951 terá sido "profundamente inspirad[a] nas experiências torguianas nas aldeias comunitárias de Rio de Onor, Castro Laboreiro e Vilarinho da Furna" (Cymbron 2015: 140), três aldeias que, como já foi salientado, aparecem frequentemente nos Diários de Torga, em trechos escritos antes de 1951 em que o autor expressou profundo pessimismo perante o futuro daquelas comunidades:

Estas pequenas comunidades que nos restam, Rio de Onor, Vilarinho da Furna, Laboreiro, etc., estão na última agonia. 0 Estado já não as pode tolerar, alheias à vida da nação, estrangeiras dentro do próprio território. (...) Por isso manda-lhes ao coração o golpe de uma estrada e a isca da caminheta dum sardinheiro. E assim, um a um se vão apagando estes pequenos enclaves, não digo de paradisíaca felicidade, mas de humana e natural liberdade. (1973b: 113-114)

Para além disso, como relembra Antunes ao comentar o sistema comunitário, os fenómenos sociais que ameaçavam Vilarinho da Furna e outras comunidades rurais com características comunitárias eram bastante patentes vários anos antes da destruição da aldeia:

É evidente que este regime comunitário, no seu processo evolutivo, hoje mais acelerado que no passado, se viria a transformar. Isso era um fenómeno facilmente previsível. (...) Mas, entre as causas do desmantelamento, que terminou com a aniquilação do regime comunitário, teremos de colocar como causa principal o espectro da barragem que de há muito ameaçava este povo. (Antunes 1985: 30)

Tão-pouco é possível afirmar que a evacuação e submersão de aldeias para construir barragens era uma prática inédita no Portugal salazarista (e depois), tendo começado nos anos trinta e afectado numerosas comunidades por todo o país (cf. Alves 2015: 30-32; Antunes et al. 2010). De facto, esta tendência foi notada pelo próprio Torga no Diário II, 
relativamente à submersão de Vidual de Baixo, em 1943: “Cuido mesmo que o que motiva a gritaria de desespero, o clamor de fim do mundo que atroa os ares, é mais o espanto do que o prejuízo. 0 pasmo de ser possível uma tal monstruosidade, e de a natureza a consentir" (Torga 1977: 198). Saliente-se ainda que, tal como no conto de 1951, a destruição desta aldeia é testemunhada por um aldeão cego que, mesmo sem ver o "tamanho físico da desgraça" (ibidem), sente-se traumatizado devido à sua topofilia para com uma comunidade em vias de desaparecimento.

No entanto, sejam quais forem as verdadeiras influências reais que Torga utilizou para a sua ficção, a relação entre a sua literatura e a história semelhante de Vilarinho da Furna não deixam de levantar questões importantes no que diz respeito à geocrítica. A saber, importa considerarmos a relação dialética entre o es paço real e o imaginário ficcional através do referente espacial porque, como comenta Bertrand Westphal, "Space oscillates between reality and fiction, but the levels are not always discernible" (Westphal 2011: 90). Robert T. Tally Jr., por sua vez, indica que a referencialidade na arte literária pode incorporar e transformar os espaços reais e os lugares fictícios na construção de um imaginário geográfico: "[T]he referentiality of fiction (and other mimetic arts) allows it to point to a recognizable place, real or imaginary or a bit of both at once, while also transforming that place, making it part of a fictional world" (Tally 2011: X). Na sua introdução à tradução inglesa da tese de Westphal, o crítico americano elabora que "Westphal understands that the referentiality operating between fiction and the "real" world is characterized by constant movement, or oscillation, as he puts it, whereby one can never really fix or pin down the referent" (idem: XI). Trata-se, de certo modo, do efeito criado pelo autor inglês Thomas Hardy ao conceber a região ficcional de Wessex, cujos topónimos reais no Sudoeste da Inglaterra são trocados por lugares ficcionais inventados pelo autor. ${ }^{14}$ Nos seus romances baseados em Wessex, os lugares fictícios na sua obra decorrem de espaços reais na sua região nativa, tal como o próprio Hardy relembra no seu "General Preface to the Wessex Edition of 1912" (prefácio ao romance Far From the Madding Crowd): 
The description of these backgrounds has been done from the real - that is to say, has something real for its basis, however illusively treated. (...) In respect of places described under fictitious or ancient names in the novels - for reasons that seemed good at the time of writing them - and kept up in the poems - discerning people have affirmed in print that they clearly recognize the originals (...). (...) The portraiture of fictitiously named towns and villages was only suggested by certain real places. (1985: $469-470)^{15}$

Ora é neste sentido, do questionamento de uma relação simples entre ficção e referencial real, que a relação ambígua entre a história de Vilarinho da Furna (e as observações de Torga sobre a mesma nos seus Diários) e o acima referido conto do mesmo autor poderiam ser bastante produtivas. Em vez de refletir uma relação mimética entre o mundo e a ficção, prática que é questionada por Westphal (cf. 2011: 75), a aldeia comunitária em "Barragem" constitui a quase substituição do lugar real pelo ficcional, devido ao que viria a ser o destino final de Vilarinho vinte anos mais tarde. Westphal considera em profundidade esta inter-ação complexa entre texto e lugar:

The text precedes the place, and sometimes seems to anticipate its discovery. (...) Conversely, the text sometimes perpetuates a place in memory, in the image that it carries. (...) The relationship of the text to the place is proleptic in some cases; in others, it is analeptic and steeped in strata that geocriticism must investigate. It sometimes happens that the text and the place overlap to the point that they end up merging. (idem: 158)

Na verdade, já alguns críticos de Torga, tais como Ana Luísa Liberato Vieira Vilela, destacaram a capacidade inventiva das comunidades rurais que aparecem na ficção de Torga: "A invenção paisagística torguiana tem, de facto, capacidade de se substituir àquilo que designa: sob esse ponto [de] vista, funciona como um estereótipo, um "simulacro" que oculta e substitui aquilo que representa" (Vilela 1994: 493). Deste modo, aquilo que a relação entre Ervedosa, em “Barragem”, e Vilarinho da Furna, no Gerês, demonstra é o papel que o próprio espaço, depois de ter influenciado um autor tal como Torga, ocupa na construção de um imaginário literário que inter-age, numa espécie de profecia, ${ }^{16}$ com o destino futuro daquele mesmo lugar. De facto, a comunidade real de Vilarinho viria a imitar 
a obra de ficção de Torga.

A este propósito, será importante considerarmos, em último lugar, a maneira como a literatura de Miguel Torga sobre Vilarinho da Furna tem contribuído para uma compreensão diferente daquela aldeia na memória cultural relativamente àquele lugar. Por exemplo, é interessante observar que, devido ao facto de Torga ter visitado e escrito tantas vezes sobre Vilarinho, a Câmara Municipal de Terras de Bouro tem desenvolvido um percurso cultural na Serra Amarela que incorpora a Barragem de Vilarinho das Furnas e o próprio Museu Etnográfico de Vilarinho da Furna, com o nome "Na Senda de Miguel Torga". ${ }^{17}$ Para além disso, ao visitar o Museu Etnográfico da antiga aldeia comunitária, depara-se com textos de vários autores, entre eles alguns trechos dos Diários de Torga. ${ }^{18}$ Voltando a Westphal, se por um lado a relação simbiótica entre o espaço e o texto informa a representação ficcional ("texts and spaces are thoroughly interconnected. Space informs the text that produces a fictional representation of a spatial referent" [2011: 169]), é igualmente verdade que o texto de um determinado autor influencia a percepção do ser humano sobre uma determinada geografia:

[T] he impact of the (fictional) text on a given space is obvious when one looks at the intertextual chain that associates spatial "reality" with fiction. The writer is the author of his city, and a given representation, even - especially? - a fictional one, eventually acts upon the realeme, affecting the way it is perceived. (ibidem)

Neste sentido, destaquemos o poema "Requiem", escrito na visita de Torga à albufeira de Vilarinho das Furnas em 1976, que aparece num lugar privilegiado no Museu Etnográfico do Campo do Gerês:

Viam a luz nas palhas de um curral,

Criavam-se na serra a guardar gado.

À rabiça do arado,

A perseguir a sombra nas lavras,

aprendiam a ler

0 alfabeto do suor honrado. 


\author{
Até que se cansavam \\ De tudo o que sabiam, \\ $\mathrm{E}$, gratos, recebiam \\ Sete palmos de paz num cemitério \\ E visitas e flores no dia de finados. \\ Mas, de repente, um muro de cimento \\ Interrompeu o canto \\ De um rio que corria \\ Nos ouvidos de todos. \\ E um Letes de silêncio represado \\ Cobre de esquecimento \\ Esse mundo sagrado \\ Onde a vida era um rito demorado \\ E a morte um segundo nascimento. (1986: 154)
}

Pode-se considerar que nestes versos, que ilustram a mitificação ("um Letes de silêncio represado") e a sacralização ("esse mundo sagrado") do povo de Vilarinho da Furna, o autor articula o impacto dos seus próprios retratos daquela aldeia sobre as percepções contemporâneas daquele lugar. Quem nunca conheceu a história da aldeia comunitária mais quintessencial, e mais trágica, de Portugal, pode compreendê-la hoje através da interpretação de Miguel Torga. Depois de a geografia ter influenciado a literatura, a literatura influencia a geografia, assim como a memória coletiva deste espaço geográfico.

Assim sendo, pode-se concluir que a relação entre a literatura de Miguel Torga, um escritor profundamente associado ao sentimentalismo pela geografia, e Vilarinho da Furna - uma aldeia com uma estrutura social quase única no século vinte e uma história invulgarmente trágica - evidencia uma relação produtiva e dialética entre obra literária e espaço geográfico real, em três principais sentidos. Em primeiro lugar, a escrita de Torga que referencia Vilarinho explicitamente articula (e contribui para) uma emoção de topofilia para com aquela aldeia nos seus Diários, que incorpora uma afeição para com o meio natural ao redor da comunidade e a memória associada à povoação, assim como o trauma e 
o sentimento de perda acarretados pela evacuação da aldeia entre 1969 e 1970 e a sua submersão em 1972. Em segundo lugar, observa-se uma relação de influência mútua entre a aldeia de Vilarinho - já existente - e a interpretação ficcional feita por Torga de uma aldeia comunitária, cujo destino final viria a ser mimetizado pelos acontecimentos na comunidade minhota vinte anos depois. Finalmente, seria interessante que qualquer investigador interessado na geocrítica visitasse o Museu Etnográfico de Vilarinho da Furna (a saber, os textos de Miguel Torga ali contidos) e a Barragem de Vilarinho das Furnas no mesmo dia, preferencialmente utilizando o percurso "Na Senda de Miguel Torga" para compreender o impacto de uma interpretação literária sobre a atitude do ser humano perante um lugar. Quando Bertrand Westphal considera a influência de Fernando Pessoa sobre a nossa percepção de Lisboa ("How can one write a line on Lisbon without looking through the spectacles of Fernando Pessoa?" [Westphal 2011: 83]), também articula perfeitamente o efeito que a obra de Miguel Torga exerce sobre nós quando olhamos para a (antiga) aldeia comunitária de Vilarinho. 


\section{NOTAS}

1 Apesar de alguns casos em que a aldeia foi referida como "Vilarinho das Furnas", este nome aplica-se apenas à barragem e não à antiga comunidade. Manuel de Azevedo Antunes aborda esta polémica no seu livro Vilarinho da Furna: Memórias do Passado e do Futuro: "já que nos tiraram a terra, deixem-nos ficar o nome: Vilarinho da Furna" (2005: 205).

2 Este Museu Etnográfico insere-se no Núcleo Museológico do Campo de Gerês, gerido pela Câmara Municipal de Terras de Bouro: http://www.cm-terrasdebouro.pt/index.php/2014-09-18-15-01-10/nucleo-museologico. o Museu também tem disponível o seguinte folheto informativo: http://www.cmterrasdebouro.pt/images/conteudo/vilarinho_porta/folheto_v_f.pdf

3 Consultar a seguinte informação sobre o projeto do Museu Subaquático: https://www.publico.pt/locallisboa/jornal/aldeia-submersa-de-vilarinho-das-furnas-transformada-em-museu-rural-subaquatico-20 4623

4 Destacam-se, entre outros textos, o estudo pioneiro de Jorge Dias intitulado Vilarinho da Furna: Uma Aldeia Comunitária (1948), Vilarinho da Furna (Análise Sociológica) de José Rodrigues Martins (1972) e Vilarinho da Furna: Uma Aldeia Afundada de Manuel de Azevedo Antunes (1985), assim como outros livros deste autor exfurnense.

5 Como se explorará mais adiante, o termo topofilia, segundo Tuan, constitui "a general framework for discussing all the different ways that human beings can develop a love of place" (Tuan 1974: XII).

6 É importante salientar que o presente texto distingue-se de uma abordagem geocrítica propriamente dita, uma vez que considera a escrita de apenas um autor sobre o mesmo espaço: "The specificity of geocriticism lies in the attention it plays to a place. The study of the viewpoint of an author or of a series of authors, which inevitably posits a form of identity, will be superseded in favor of examining a multiplicity of heterogeneous points of view, which all converge in a given place, the primum mobile of the analysis" (Westphal 2011: 127). Dito isto, certos elementos da tese de Westphal, tais como o papel da referencialidade na construção de um imaginário literário e a relação mútua entre texto e espaço, ser-nos-ão úteis aqui.

${ }^{7}$ Estes valores e estruturas sociais eram ainda mais invulgares tendo em consideração a governação ditatorial no Portugal da época.

${ }^{8}$ A presença de características comunitárias na aldeia de Rio de Onor Norte ainda no século vinte (embora em menor grau) foram suficientemente evidentes para levar Jorge Dias a escrever Rio de Onor: Comunitarismo Agro-Pastoril (1953), um livro sucessor ao seu estudo sobre Vilarinho da Furna.

N. ${ }^{\circ} 38-6 / 2018$ | 247-270 - ISSN 2183-2242 | http:/dx.doi.org/10.21747/21832242/litcomp38a14 
9 A título de exemplo, consultar Paulo Carvalho, "Geografia e paisagem no universo literário de Miguel Torga" (2012); Francisco Armando Angélico Choupina, O Lugar do Meio: uma Leitura Geográfica de Miguel Torga (2005); Pedro Rogério Couto Moreira, Geografia Sentimental de Miguel Torga em Minas e Outros Escritos (2016).

10 Embora as dissertações de Mateus e Cymbron destaquem a importância de três aldeias comunitárias nos Diários e na mundivisão do autor - Rio de Onor, Vilarinho da Furna e Castro Laboreiro (Mateus 2006: 161162; Cymbron 2015: 47) - Torga escreve sobre Vilarinho com mais frequência nos seus Diários, e atribuí mais importância simbólica àquela aldeia específica.

${ }^{11}$ Cymbron acrescenta que o estudo de Jorge Dias sobre Vilarinho da Furna foi igualmente uma influência sobre o comunitarismo de Torga (2015: 4-5).

12 Isabel Mateus relembra que "o eu rebela-se contra esta atitude das forças do Governo porque já nem aqui, (seu) local eleito de reencontro e de identificação e de identificação com o meio físico e a pureza da primitiva natureza humana, futuramente poderá encontrar a democracia que ele pretenderia estender ao resto do país." (2006: 162)

13 Saliente-se, no entanto, que o nome da aldeia ficcional neste conto relaciona-se com a geografia real de Portugal, uma vez que existem três aldeias no país com o mesmo topónimo (embora não comunitárias): Ervedosa no distrito da Guarda, Ervedosa no distrito de Bragança, e Ervedosa do Douro no distrito de Viseu.

14 Já alguns críticos estableceram uma relação entre a escrita de Thomas Hardy e a de Miguel Torga. Consultar Antony Cardoso Bezerra, "Entre Wessex e a Montanha: Da aldeia ao mundo pelos contos de Thomas Hardy e de Miguel Torga" (2010).

15 J. Hillis Miller, no seu livro Topographies (1995), considera em mais profundidade a relação problemática entre topografia e geografia, utilizando a ficção de Thomas Hardy como ponto de partida.

16 Para um estudo mais extenso de Miguel Torga enquanto profeta, consultar Maria João Reynaud, "Miguel Torga: Poeta / Profeta" (2008).

17 Consultar o mapa deste percurso na página web da Câmara Muncipal de Terras de Bouro: http://www.cmterrasdebouro.pt/rede_trilhos_pedestres/files/PR-05.pdf

18 Para além das citações de Torga, encontram-se no Museu textos de Jorge Dias, Orlando Ribeiro e Manuel de Azevedo Antunes, entre outros. 
Peter Haysom

\section{Bibliografia}

Alves, Osvaldo Marco (2015), As Barragens e o Património de Comunidades Afogadas: Estudo Comparativo de Vilarinho das Furnas e Guapé. Dissertação do Mestrado. Porto: Faculdade de Letras da Universidade do Porto.

Antunes, Manuel de Azevedo (1985), Vilarinho da Furna: Uma Aldeia Afundada. Lisboa: A Regra do Jogo.

-- (1994), Requiem por Vilarinho da Furna: Uma Aldeia Afundada. Lisboa: Biblioteca da Universidade Lusófona.

-- (2005), Vilarinho da Furna: Memórias do Passado e do Futuro. Lisboa: Centro de Estudos da População, Ambiente e Desenvolvimento.

Antunes, Manuel de Azevedo; DUARTE, Lucina Coutinho; REINO, João Pedro (2010), "Barragens de Portugal: de Vilarinho da Furna à Aldeia da Luz, com passagem pelo Douro Internacional", in Revista Lusófona de Humanidades e Tecnologias, [S.l.], No. 10, Dez. 2010, 13-21.

Bezerra, Anthony Cardoso (2010), “Entre Wessex e a Montanha: Da aldeia ao mundo pelos contos de Thomas Hardy e de Miguel Torga", in José Rodrigues da Paiva (Ed.) Estudos Sobre Miguel Torga. Pernambuco: Associação de Estudos Portugueses Jordão Emerenciano, 75-106.

Carvalho, Paulo (2008), "Literatura, paisagem e geografia histórica: revisitar Miguel Torga a pretexto dos ambientes de montanha", in Cadernos de Geografia, No. 26/27 (2007-2008), 77-83.

-- (2012), “Geografia e paisagem no universo literário de Miguel Torga: A Cordilheira Central através do Diário (1932-1993)", in Revista da Faculdade de Letras - Geografia, Universidade do Porto III série, vol. I, 2012, 45-58.

Coentrão, Abel (2003), “Aldeia submersa de Vilarinho das Furnas transformada em museu

N. ${ }^{\circ} 38-6 / 2018$ | 247-270 - ISSN 2183-2242 | http:/dx.doi.org/10.21747/21832242/litcomp38a14

266 
rural subaquático", Público, edição online, 24 de agosto de 2003, https://www.publico.pt/2003/08/24/jornal/aldeia-submersa-de-vilarinho-das-furnastransformada-em-museu-rural-subaquatico-204623 (acedido em 27/09/2017).

Choupina, Francisco Armando Angélico (2005), o Lugar do Meio: uma Leitura Geográfica de Miguel Torga. Dissertação de Mestrado. Coimbra: Faculdade de Letras da Universidade de Coimbra.

Cymbron, José Manuel (2015), O Portugal de Miguel Torga (Um Itinerário em Casa do Orfeu Rebelde). Dissertação de Doutoramento. Porto: Universidade Fernando Pessoa.

Dias, Jorge (1981), Vilarinho da Furna: Uma Aldeia Comunitária. Maia: Imprensa NacionalCasa da Moeda [1948].

Gago, André (2010), Rio Homem. Rio de Janeiro: Leya.

Hardy, Thomas (1985), "General Preface to the Wessex Edition of 1912", in Far From the Madding Crowd. London: Penguin, 467-472.

Lisboa, Maria Manuel (2000), "Por(Torga)lidade or Torga and the Motherland: Still Angry After All These Years", in Charles M. Kelley (Ed.), Fiction in the Portuguese-Speaking World. Cardiff: University of Wales Press, 22-45.

Lousada, Vítor (2003), Miguel Torga: O Simbolismo do Espaço Telúrico e Humanista nos Contos. Guimarães: Cidade Berço.

-- (2012), Viajar com...Miguel Torga. Guimarães: Opera Omnia.

Martins, José Rodrigues (1972), Vilarinho da Furna (Análise Sociológica), Separata da Revista Bracara Augusta, Vol. XXIV, Janeiro-Dezembro de 1970.

Mateus, Isabel Maria Fidalgo (2006), A Viagem de Miguel Torga. Dissertação de Doutoramento. Birmingham: University of Birmingham.

Miller, J. Hillis (1995), Topographies. Stanford: Stanford University Press.

Moreira, Pedro Rogério Couto (2016), Geografia Sentimental de Miguel Torga em Minas e 
Peter Haysom

Outros Escritos. Separata de Revista da Academia Mineira de Letras. Belo Horizonte/Brasília: Oficinas da Thesaurus Editora de Brasília.

Outeirinho, Maria de Fátima (2016), "Do lugar do(s) mapa(s) na viagem e seu relato ou muito para além de um atlas oficial", in Cadernos de Literatura Comparada No.34 06/2016, 191-203.

Reynaud, Maria João (2008), "Miguel Torga: Poeta / Profeta”, in Maria de Fátima Martinho (Ed.), Actas do Colóquio Comemorativo do Nascimento de Miguel Torga - Faculdade de Letras da Universidade do Porto, 22 e 23 de Novembro de 2007. Porto: Faculdade de Letras da Universidade do Porto, 167-173.

Santana, Maria Helena (2008), "Notícias do Paraíso: O povo rural nos contos de Miguel Torga", in Maria de Fátima Martinho (Ed.), Actas do Colóquio Comemorativo do Nascimento de Miguel Torga - Faculdade de Letras da Universidade do Porto, 22 e 23 de Novembro de 2007. Porto: Faculdade de Letras da Universidade do Por to, 155-165.

Tally Jr., Robert T. (2011), “Translator's Preface”, in Bertrand Westphal, Geocriticism: Real and Fictional Spaces. Trad. Robert T. Tally Jr. New York: Palgrave Macmillan [2007], IXXIII.

Torga, Miguel (1951), Pedras Lavradas. Coimbra: Coimbra Editora.

-- (1973a), Diário XI. Coimbra: Coimbra Editora [1973].

-- (1973b), Diário III. Coimbra: Coimbra Editora [1946].

-- (1973c), Diário IV. Coimbra: Coimbra Editora [1949].

-- (1974), Diário V. Coimbra: Coimbra Editora. [1951].

-- (1976), Diário VIII. Coimbra: Coimbra Editora. [1959].

-- (1977), Diário II. Coimbra: Coimbra Editora [1943].

-- (1986), Diário XII. Coimbra: Coimbra Editora [1977].

-- (1989), Diário I. Coimbra: Coimbra Editora [1941]. 
-- (2000), Portugal. Alfragide: Dom Quixote [1950].

"Trilho da Águia do Sarilhão", Rede de Trilhos Pedestres "Na Senda de Miguel Torga", Câmara Municipal de Terras de Bouro, folheto online, http://www.cmterrasdebouro.pt/rede_trilhos_pedestres/files/PR-05.pdf_ (acedido em 28/09/2017).

TUAN, Yi-Fu (1974), Topophilia: A Study of Environmental Perceptions, Attitudes and Values. New York/Chichester: Colombia University Press.

"Vilarinho da Furna: 3a Exposição Etnográfica", Museu Etnográfico de Vilarinho da Furna, Núcleo Museológico do Campo do Gerês: http://www.cmterrasdebouro.pt/images/conteudo/vilarinho_porta/folheto_v_f.pdf_(Museu visitado em 27/06/2017; folheto online acedido em 28/09/2017).

Vilarinho das Furnas (1971), filme realizado por António Campos. Lisboa: Tobis Portuguesa Nacional Filmes.

VILELA, Ana Luísa Liberato Vieira (1994), "Mitos viris na simbólica da paisagem torguiana”, in Aqui, Neste Lugar e Nesta Hora: Actas do Primeiro Congresso Internacional sobre Miguel Torga. Porto: Edições Universidade Fernando Pessoa, 493-504

WESTPHAL, Bertrand (2011), Geocriticism: Real and Fictional Spaces. Trad. Robert T. Tally Jr. New York: Palgrave Macmillan [2007]. 
Peter Haysom

Peter Haysom é licenciado em Línguas Modernas pela Universidade de Cambridge e Mestre em Estudos Literários, Culturais e Interartes pela Universidade do Porto. Neste momento é doutorando em Estudos Portugueses e Lusófonos na Universidade de Nottingham, com o apoio da Midlands3Cities AHRC Doctoral Training Partnership. As suas áreas de interesse académico incluem a geocrítica, o regionalismo e a identidade regional, por exemplo no seu ensaio "'Obsessiva eternidade': O fim do mundo rural, segundo Aquilino Ribeiro", in Materiais para o Fim do Mundo No. 7 (Porto: Instituto de Literatura Comparada Margarida Losa, 2017). 